\title{
On "Amazonia"
}

\section{ROGER BEEBE}

Professor, Department of Art, the Ohio State University

\begin{abstract}
This essay grows out of Amazonia, a 2019 short "desktop cinema" essay film about the cities where Amazon.com had their four original distribution centers. The film uses those cities as a way of thinking about how the virtual economy is transforming real space. Using the film as a starting point, the essay focuses on the specific forms of labor necessitated by e-commerce, exploring most specifically the labor of the "warehouse associates" who perform the manual labor necessary to produce the apparent magic of online purchases. The essay ends with a consideration of the persistence of older forms of physical labor despite the push to automate some parts of these jobs.
\end{abstract}

Let's begin here: https://vimeo.com/351213988/e7ea8c312f

This is a sequence from my 2019 film Amazonia, about which more shortly. The text in that clip is from an Amazon.com job listing from their 18-month 2018-19 "high-volume hiring" push, which sought to add an additional 100,000 workers, bringing their global labor force somewhere north of 600,000 employees. ${ }^{1}$ The math on that 600,000 can be a little fuzzy, depending on whether one counts their substantial seasonal workforce - estimated at around 120,000 - who are taken on just to satisfy our increased holiday demand; the workers at the companies they've acquired, like Whole Foods - another 87,000 or so; subcontractors who handle an increasing number of their deliveries; and so on. No matter how one counts, though, the point is the same: they're gigantic, and growing at an unprecedented pace.

A substantial number of these workers are "warehouse associates," the position that the job listing in that clip is advertising. Their numbers weren't always so daunting. When I started working on my film in 2005, Amazon relied primarily on four "fulfillment centers"- their term for these warehouses where the 400 million or so products available for purchase on their website await our orders-located in rather remote locations that were chosen largely for their favorable local tax environments. With this relatively limited footprint, Amazon had a mere 12,000 employees in total. 


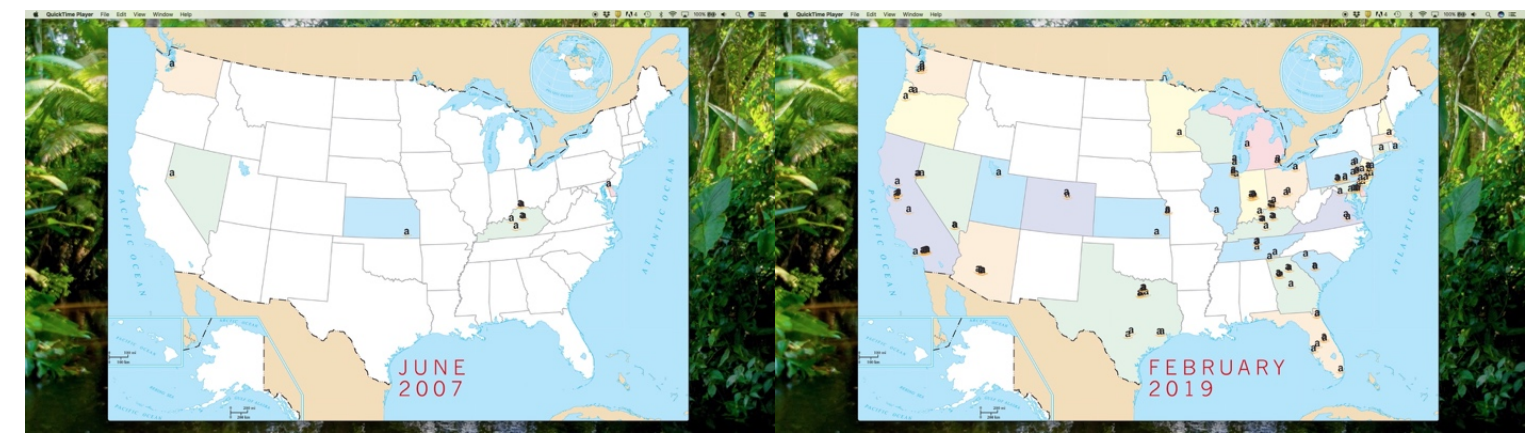

Figure 1. The location of Amazon fulfillment centers 2007/2019-animated time-lapse sequence at https://vimeo.com/351214540/9d143c8f77

But the past dozen years have seen a dramatic change in Amazon's business model. The company now operates more than 100 facilities in more than 30 states, with dozens more projected for the current year alone. (It's no coincidence that this period of rapid growth coincided with the closing of their tax loopholes, as state after state sought to collect sales taxes from online retailers, even when their warehouses were located elsewhere.) The rapid expansion of their empire of distribution centers has simultaneously produced an astronomical growth in their workforce. They're the fastest growing company in U.S. corporate history, the first American enterprise to reach 300,000 employees in less than 20 years. Their labor force has grown tenfold in just the last six years, driven largely by the staffing needs of these scores of new facilities.

The focus of my film wasn't initially on the workers and working conditions at these sites. What originally animated the project was a desire to represent how the virtual economy exists in and transforms physical space. It occurred to me that we don't give much thought to where these hundreds of millions of items exist in real space, nor do we consider how the products get from those locations to our doorstep in just a matter of days or even hours. In 2005, I made my first visits to the four cities where Amazon's primary fulfillment centers were locatedCampbellsville, KY; Coffeyville, KS; Fernley, NV; and New Castle, DE-shooting several rolls of Kodachrome Super 8 film in each city. I split my shooting between the warehouses and the towns themselves, hoping somehow to capture in images of the architecture the ways that ecommerce was transforming these towns. 


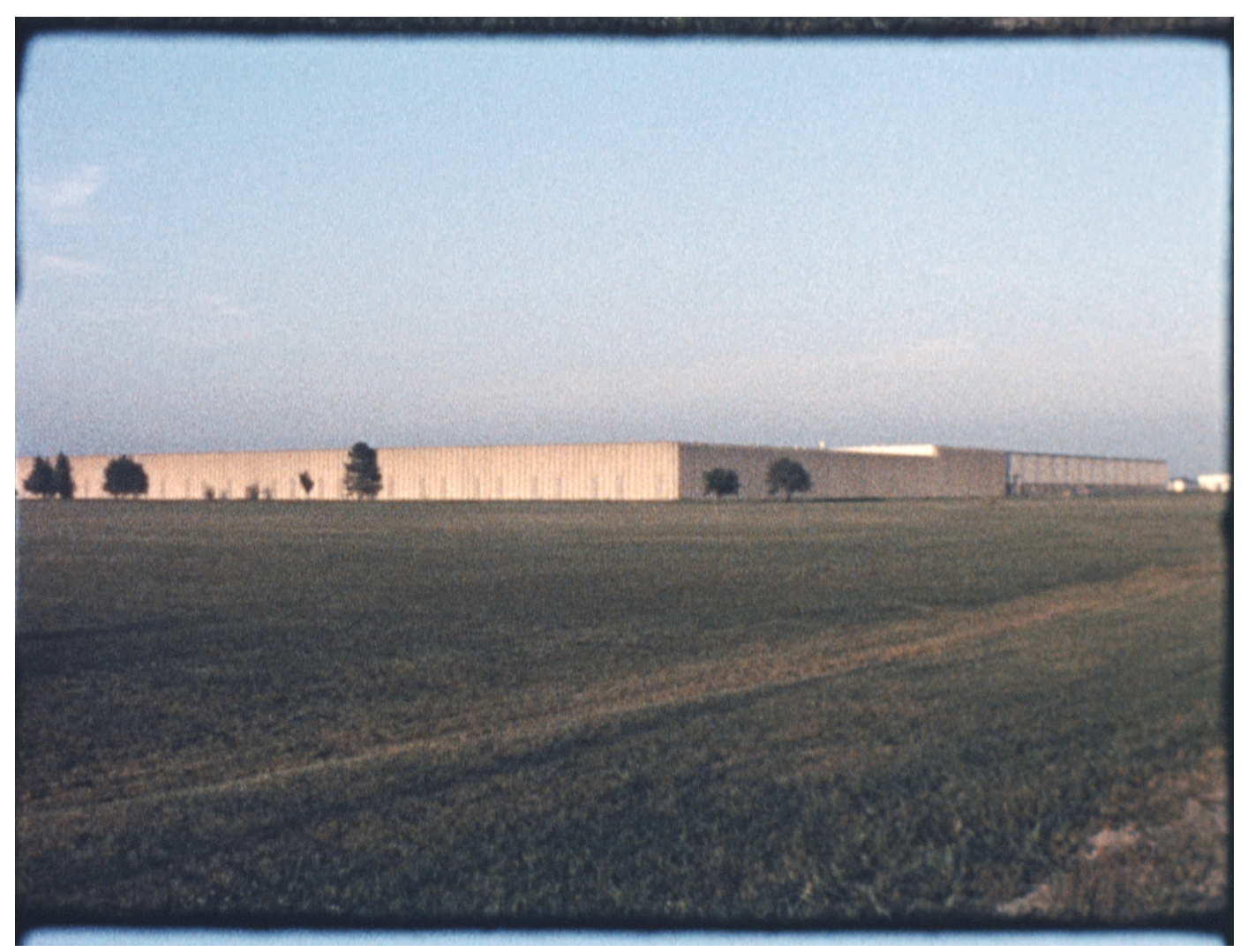

Figure 2. Amazon fulfillment center in Coffeyville, KS

But the distribution centers are generic - sometimes repurposed from pre-e-commerce businesses (like the former Golden Books warehouse in Coffeyville, KS), sometimes custom-built with an eye to utility alone - and their exteriors betray none of the historical specificity of what is contained within. The towns themselves were also transforming spatially and architecturally, but in a way that didn't reveal the specific source of their newfound prosperity. Most had new strip malls with big-box stores that had expanded after the arrival of Amazon, like the then-underconstruction Big Lots! in Campbellsville, KY or the similarly in-progress Walmart Supercenter in Coffeyville, which was being built to replace an older "regular" Walmart. We think of ecommerce as the enemy of bricks-and-mortar retailers, but in these towns, Amazon is actually underwriting a boom in big box stores. If this was the way that this new economic order was expressing itself in architecture, maybe this new order wasn't so new after all. 


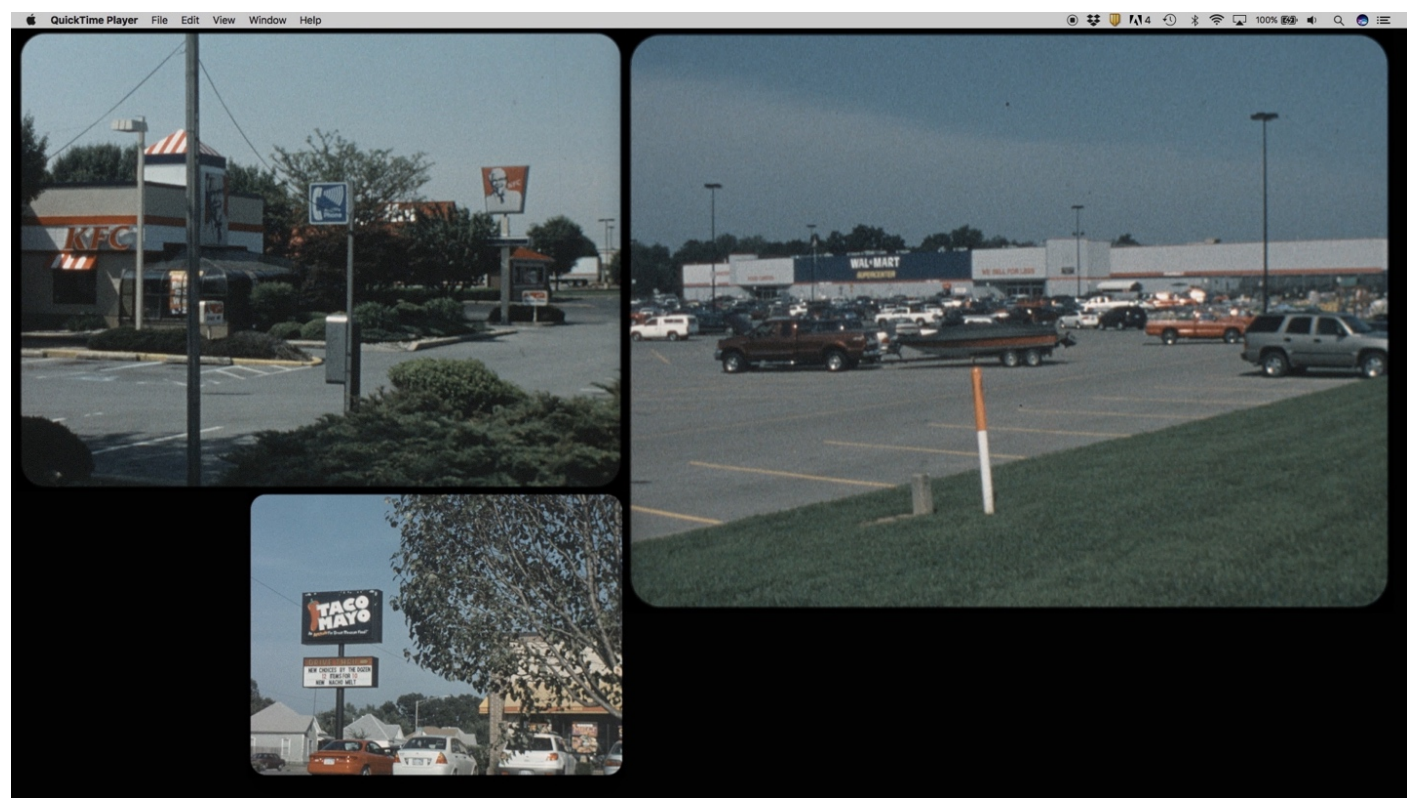

Figure 3. A still from Amazonia featuring strip mall sprawl in New Castle, DE, Campbellsville, $\mathrm{KY}$, and Coffeyville, $\mathrm{KS}$

Over the following half-decade I made subsequent trips to each town, hoping to find what I hadn't discovered on those first trips, and explicitly began to focus more on local residents. (That I didn't start by focusing on the people may seem surprising, but in several of my past films I've been more successful at detailing changes in the world through the representation of the built environment alone.) On these later trips, in addition to shooting more Super 8 of the built environment, I also shot some black-and-white $16 \mathrm{~mm}$ footage of the residents going about their daily lives and made sound recordings of active public spaces and my direct interactions with members of the community: at a skate park, a late-night cornhole game, the Dalton Defenders Museum, the Campbellsville Chamber of Commerce, and so on. While some of this new footage and sound did find its way into the project, it didn't prove to be the missing piece that completed the puzzle of this film.

I realized that I really needed to know what was happening inside those warehouses - to people's bodies, their labor, and their lived experiences — but access to those spaces and images of them is very tightly controlled. The form of labor specific to these fulfillment centers is unfamiliar to most of us, less easily pictured than the kinds of labor that typified earlier eras like, say, garment workers in a factory in Southeast Asia or on an automobile assembly line across the Mexican border. Both examples are emblematic of globalization, of course, but are also just relocations of older forms of industrial labor from the U.S. into the developing world. What exactly does an Amazon "warehouse associate" do? What does this labor look like? What toll does it take? 


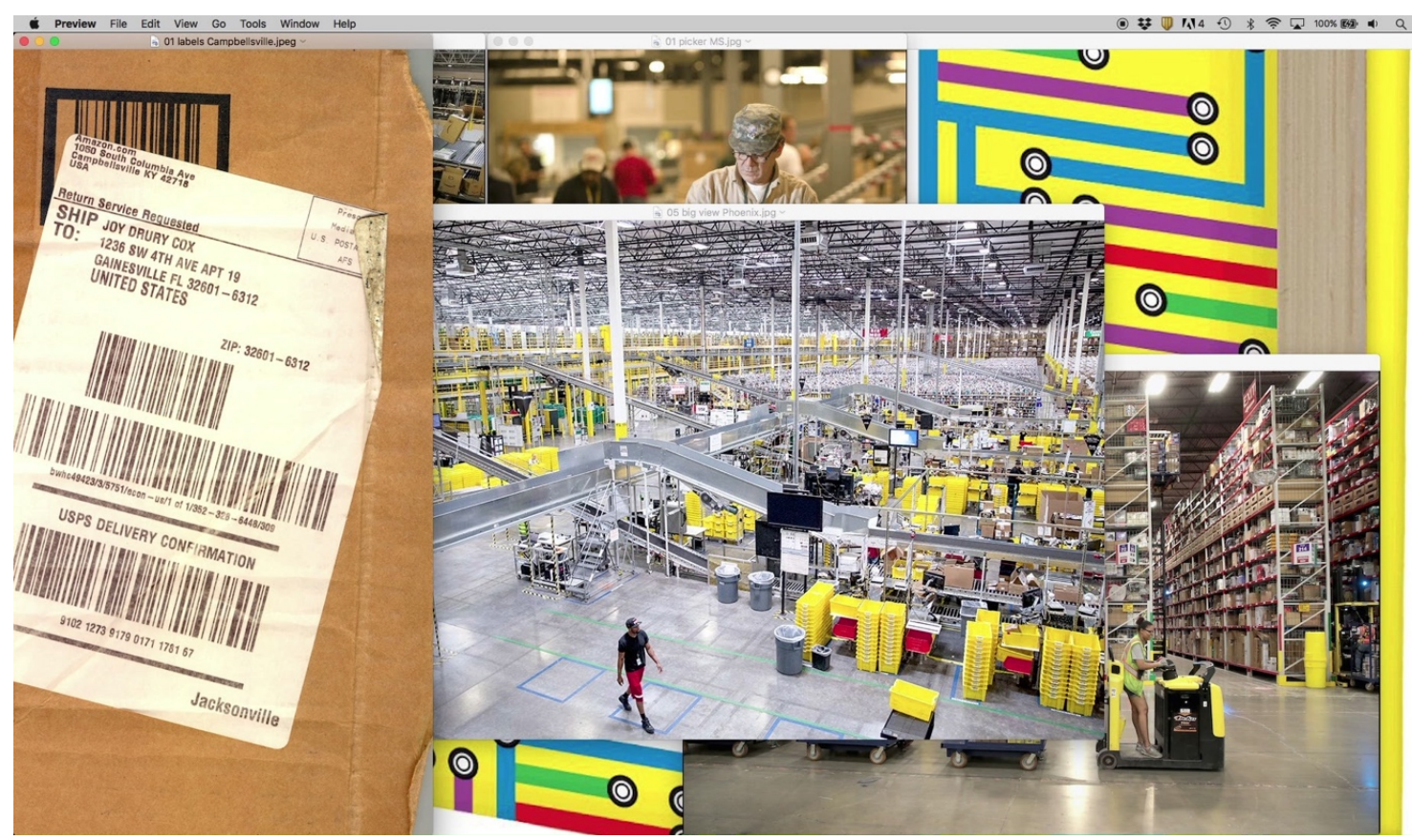

Figure 4. A still from Amazonia featuring images of the interiors of Amazon warehouses from the few articles where cameras were allowed inside the fulfillment centers

This is where I return to the job posting explored in the video clip that opened this essay. It turns out that Amazon's own description of the duties involved in these jobs is explicit about how punishing they can be (even if couched in a language designed to seem slangy and fun). I stumbled on this document late in the process of making the film-May 2017-but it proved key to solving the dilemmas I'd been facing. Alongside trumpeting their "relaxed dress code"_- "it's Casual Friday every day" - the posting also warns applicants that they "must be able to lift up to 49 pounds with or without reasonable accommodation, stand/walk for 10-12 hours" and that "noise level varies and can sometimes be loud" and temperatures "will occasionally exceed 90 degrees." 


\section{amazon}

My Job Portal

\section{Full-Time Warehouse Associate}

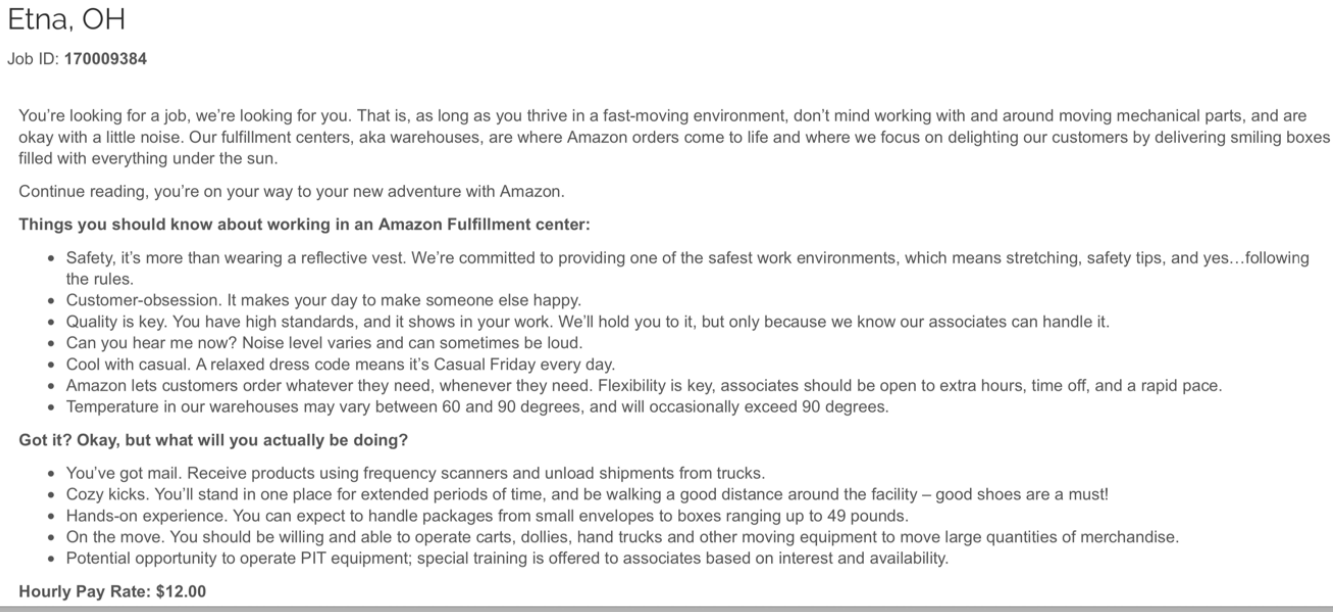

\section{Figure 5. Typical Amazon job listing for a "full-time warehouse associate"}

A number of journalists have investigated how these warnings play out in practice. Senior citizens whose retirement funds were gutted by the 2008 market crash now walk 10-15 miles per shift as "pickers," the workers who collect and pack your orders. Employees are forced to urinate in bottles because the time allotted for breaks is insufficient for making the trip across the warehouse to the restrooms. Workers collapse from heat exhaustion on the hottest days, and management has ambulances at the ready to ferry them to the hospital rather than shutting down operations. The horror stories are too numerous to detail in full, but in sum, Amazon is true to its word about the demands that these warehouse jobs make on their employees' bodies. These jobs are taxing to workers' psyches as well-The Daily Beast has documented 189 suicide attempts by desperate Amazon warehouse workers between 2013 and 2018. ${ }^{2}$

These journalistic accounts are compelling and even devastating. But in the end, I still returned to my film and to the specific project I had articulated for myself: how to represent the physical transformations effected by the virtual economy.

The final form of the film was developed initially for two different live-performed versions that I presented as part of a 23-city tour in 2018 and then refined while in residence at the Headlands Center for the Arts in early 2019. That form attempts to solve the problems I had originally encountered - about the built environment not really reflecting the radical shift in the economic order that it issues from - by situating my footage of these warehouses and towns on a computer 
desktop. Within the multi-window space of the desktop, this footage is immediately thrown into contact with other narratives and images drawn from the journalistic articles I've been referencing as well as science fiction and popular culture, all of which help to flesh out and contextualize my footage and to afford occasional glimpses inside those heavily guarded spaces.

I've been calling this form "desktop cinema," adapted from the title of a program from the 2018 Flaherty Film Seminar on the "Cinema of the Desktop."3 The collapsing of the cinema frame and the computer desktop allows my film to point to the mechanism by which these spaces and this labor are dematerialized, turned into the magic of mouse clicks and touch screens, which may be one key to understanding the ease with which this erasure of labor occurs. Of course, as Marx theorized almost two centuries ago, the commodity form itself works to obscure labor value and mystify the social relations that subtend our economic order. ${ }^{4}$ A big part of the project of the film is to demystify those social relations and to bring the labor into the light of day. The internet is simultaneously what allows for a further distancing from actual labor in our present moment (so that we never even have to occupy the same retail space as those doing the physical work to make our shopping experience possible). But at the same time, the internet allows us the possibility of reconnecting with that distant site of labor. Amazonia uses the desktop cinema form to activate the space of the computer desktop and its networked connectivity to dramatize our passage through that interface to other, real spaces on the other end of these transactions. By using grainy remediated Super 8 and $16 \mathrm{~mm}$ film as the primary modes for representing those real spaces (as opposed to the glossy surfaces of the HD video image), I have attempted to insert some materiality into this interface, as a metonym for the physical labor happening in those far-flung warehouses.

Amazonia is motivated by the central representational dilemma that Fredric Jameson points to in the final section of his canonical essay on postmodernism: how to produce a "cognitive mapping" of the relationship of the individual to the flows of global capitalism. ${ }^{5}$ While previous moments in the development of capitalism lent themselves to a simpler understanding of the relationship between the exploited and the exploiters - say the shop boss and the workers on the factory floor, or London as the seat of the British Empire in relationship to its colonies-our current moment has proven much more difficult to conceptualize or imagine.

By summoning the interface through which we interact (at a distance) with the workers in these fulfillment centers, the film creates a cognitive mapping that connects the (remote) moments of consumption and production, hopefully in a way that both implicates the consumer in the kind of labor that takes place within those centers and restores some political agency to the individual, some ability to transform that system. The mapping is networked, decentered/decentralized, and rhizomatic, and this differentiates it from the ways we have mapped our relationship to previous historical moments and economic orders, which in various ways presumed some central arborescent root (to continue the Deleuzian botanical metaphor). ${ }^{6}$ Further, these networks aren't just informatic - they also get materialized in physical space, with the logistical and 
transportation networks needed to move the objects to and from these warehouses as well as within them. These physical transportation networks work in parallel to the more concealed physicality of computer networks, which also have a substantial material footprint-fiber-optic cables, server farms, and so on. ${ }^{7}$ The material infrastructure that supports this virtual economy offers a parallel to the physical exploitation that subtends the magic of e-commerce.

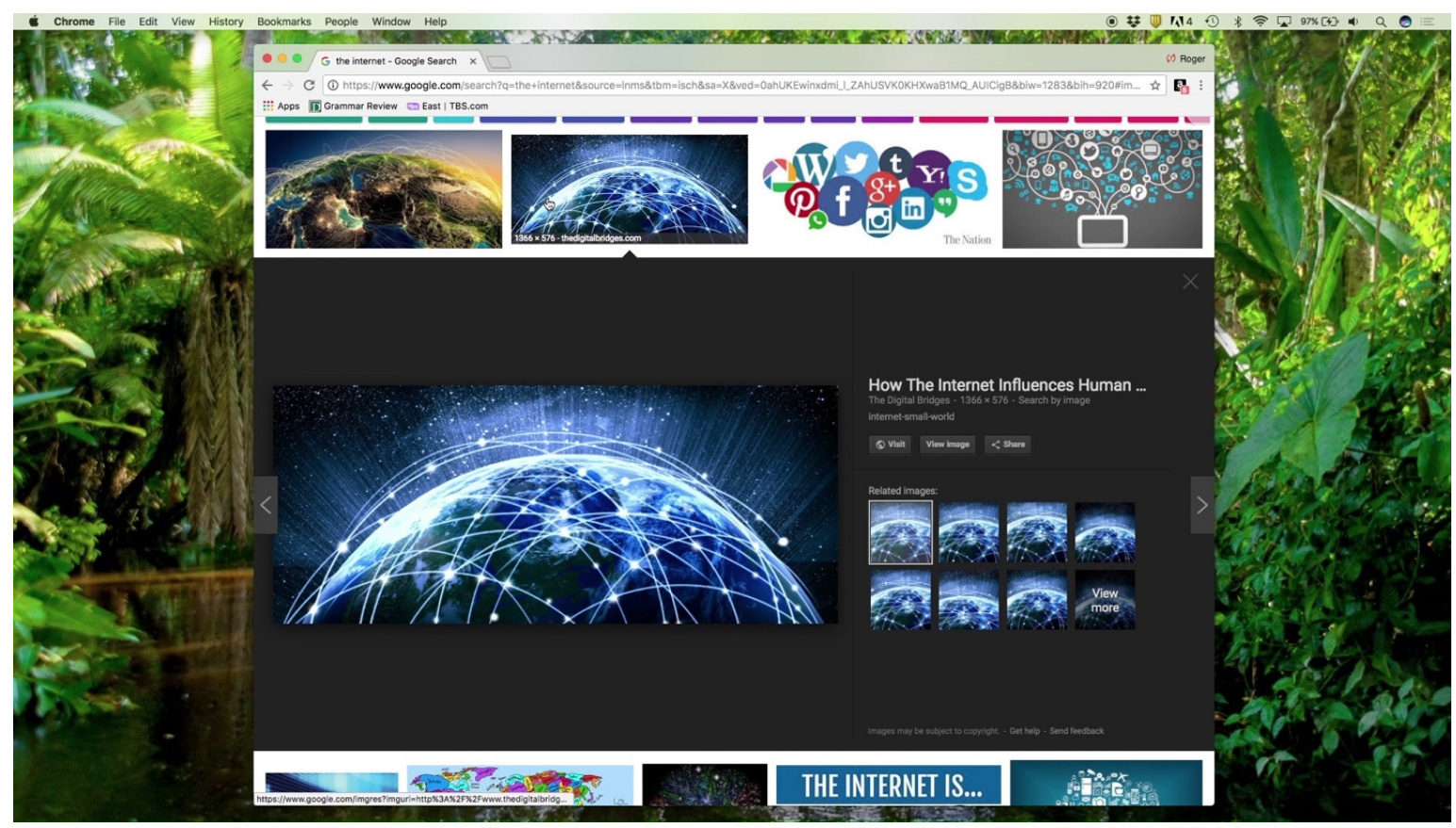

Figure 6. Google image searching "the internet" to establish the "desktop cinema" essay form in Amazonia

Amazonia documents the trajectory of my own thinking, moving from the built environment to the question of labor as the central focus of the project. ${ }^{8}$ One could argue that the tightly regulated forms of labor in these fulfillment centers - where the smallest movements and gestures are analyzed, measured, and timed like a Taylorist dream come true — are emblematic forms of work in the digital economy - alongside the gig work and microlabor performed by Uber drivers, TaskRabbits, and Mechanical Turks. My hope is that Amazonia renders visible the connections between the moment of consumption - the magic click of the order button on a website - to the grueling, behind-the-scenes labor that enables it. In doing so, the film offers a cognitive mapping first step toward understanding our own implication in this system - and our potential political agency to change it.

Since I'm now moving into terrain that's unmapped by my film — into the rapidly changing terrain of Amazon's own vision of its future - it's an appropriate moment to share the full film with you and to suggest a 25-minute step away from this essay:

https://vimeo.com/332990033/7f7d3dbb38 
The film documents the changes of the past decade-plus of Amazon's history and the current organization of its workforce, a provisional situation that will inevitably and rapidly evolve. In fact, many of the recent stories about Amazon focus on their attempts to end their current reliance on physical labor. Amazon has recently welcomed cameras into their fulfillment centers - at least more than they've done historically — but when they do so, it's largely to highlight their futuristic technologies rather than to dramatize the hard-working humans scrambling around these spaces the size of eight football fields. They're promoting a fantasy of automation where human labor is replaced by benevolent mobile robotic shelves that will bring products to workers rather than workers traversing miles of warehouse floor each shift to retrieve them by hand. Boasting that their packages average less than a minute in the hands of a human on their way out of the warehouse, Amazon pitches a futuristic vision of rapid delivery by an army of drones and autonomous vehicles. A recent article in The New York Times notes that Amazon is currently undertaking a massive $\$ 700$ million effort to retrain a third of its American workforce, in order to prepare them to take on high-tech tasks once their physical labor becomes obsolete. ${ }^{9}$ One could ask, has Amazon ended the need for strenuous physical labor inside their fulfillment centers?

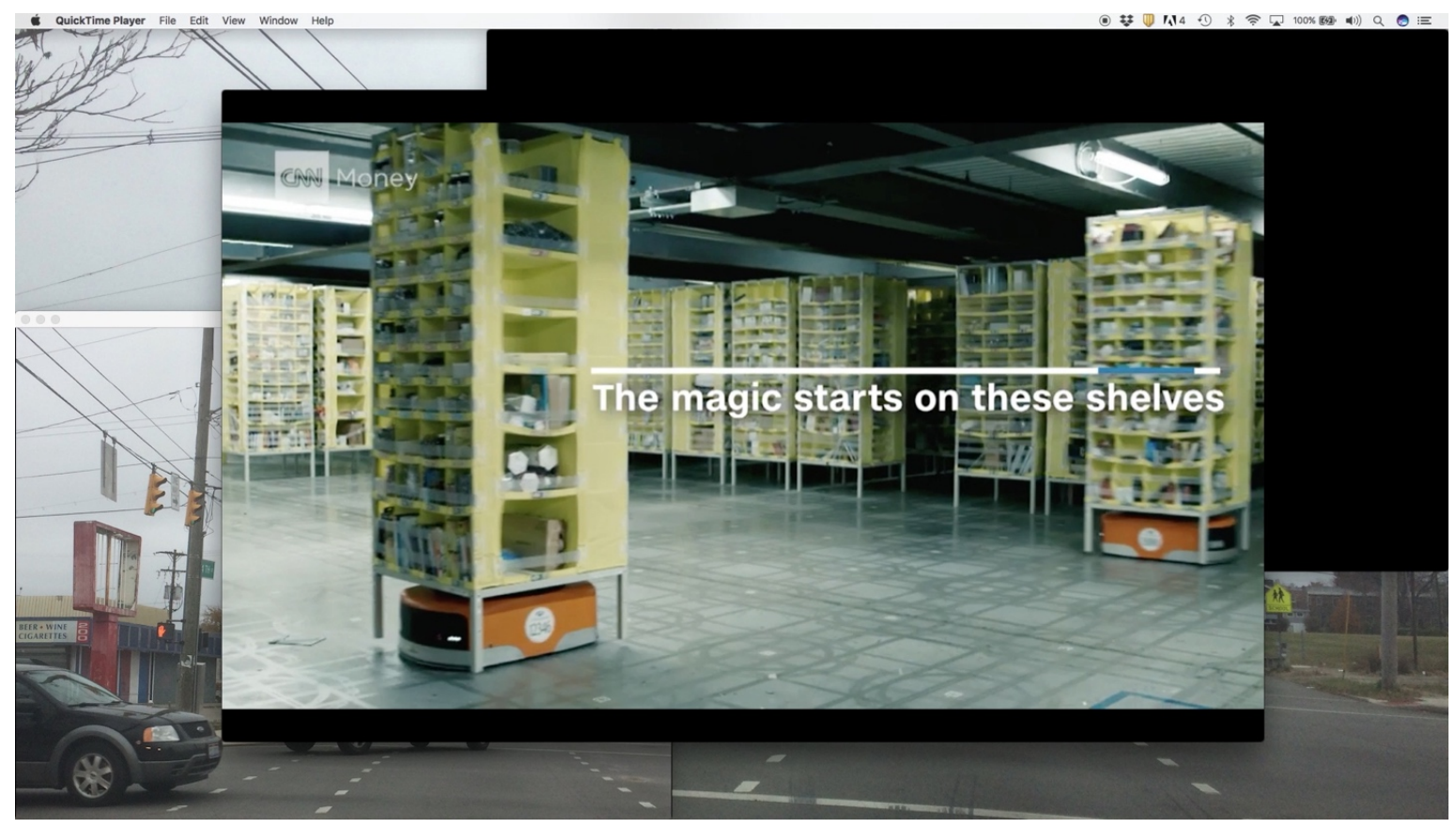

Figure 7. Still from Amazonia showing the "magic" robotic shelves from a recent CNNMoney feature

New technologies that promise to free us from the demands of physical labor often produce new forms of exploitation. Even if we believe the Amazon PR pitch in that New York Times story, retraining a third of their workforce will still leave several hundred thousand workers languishing in unskilled, laborious, low-wage jobs. Moreover, there is no indication that we've reached the point where automation will keep pace with the simple need for bodies. Automation is a process, 
not an absolute. The miles of conveyor belts already deployed in these warehouses may replace what previously would have been human labor, but this does not result in the end of all forms of physical labor-far from it.

Amazon's PR has tended to focus on their fantasies (and ours) of the end of physical labor-the automated shelves, the army of delivery drones - but those fantasies hide the persistence of incredibly taxing forms of labor in these warehouses and in the delivery of these purchases to their consumers. These much-publicized efforts seem designed less to replace human labor completely than to signal to the public that Amazon is a company of the future with a vision drawn from science-fiction imaginary.

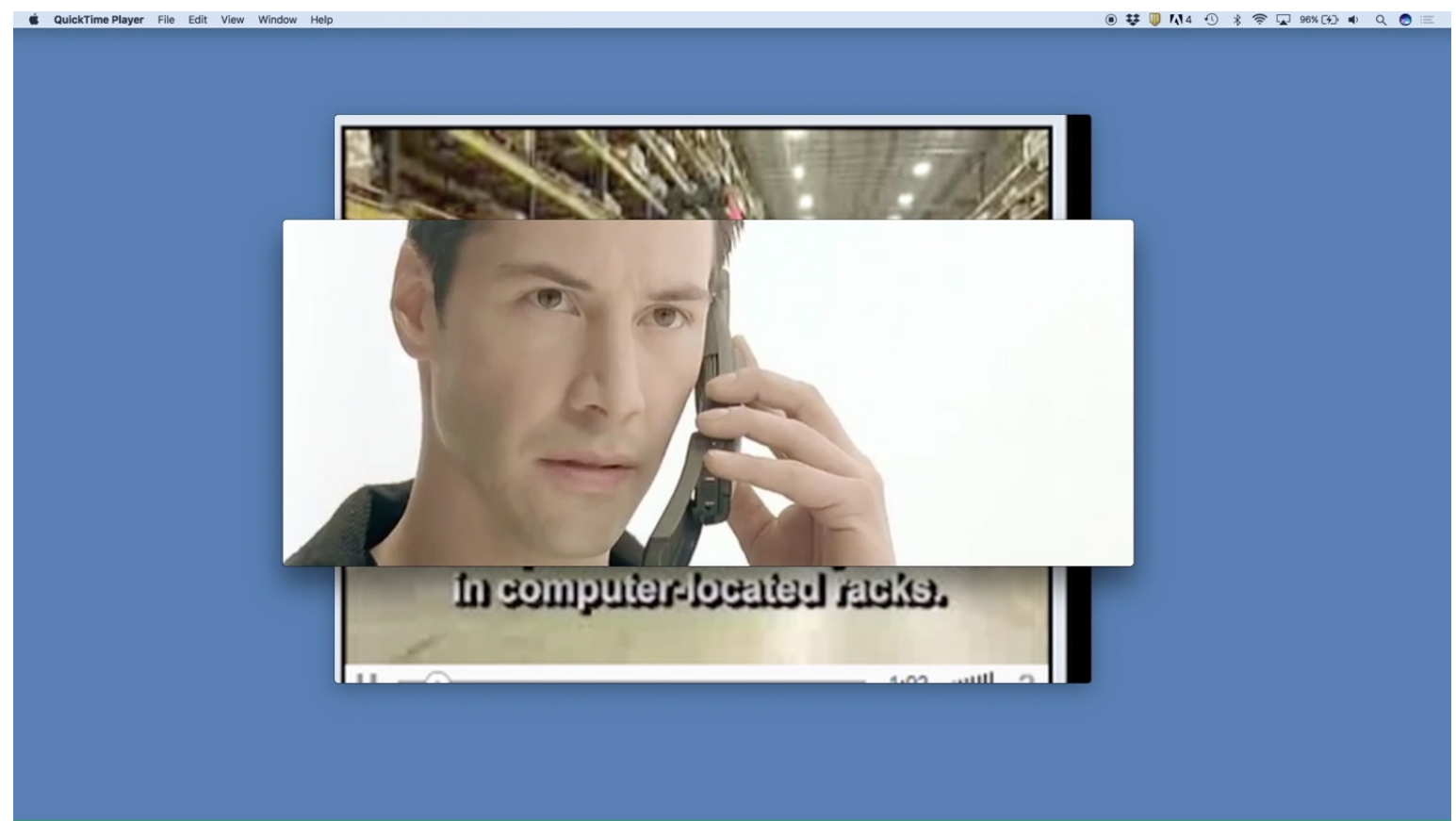

Figure 8. A still from Amazonia, putting The Matrix's science fiction vision into conversation with the high-tech fantasy from an Amazon recruiting video

Ultimately, although the precise nature of the labor that Amazon demands of their lowest-paid employees will change in the months and years ahead, it's clear that we are far from the utopian fantasy where automation frees all humans from toil. It is critically important that in our efforts to understand emergent forms of digital labor in the age of automation, we do not overlook the persistence of physical labor for hundreds of thousands of Amazon employees around the U.S. and the world. 


\section{ENDNOTES}

1. “Amazon's Wild 24-Year Ride, from 11 Employees to 600,000-plus," Fast Company, April 11, 2019, https://www.fastcompany.com/90331689/amazons-wild-24-year-ride-from-11-employeesto-600000-plus.

2. “Colony of Hell': 911 Calls from Inside Amazon Warehouses," The Daily Beast, last updated August 5, 2019. https://www.thedailybeast.com/amazon-the-shocking-911-calls-from-inside-itswarehouses.

3. https://www.academia.edu/35847256/Cinema_of the_Desktop_Flaherty_2018. The Flaherty program included films and videos stretching back decades (at least in some germinal version of the form), with a more substantial cluster of contemporary work.

4. Karl Marx, Capital, Volume 1 (New York: Vintage Books, 1977), especially 163-177.

5. Fredric Jameson, Postmodernism, or the Cultural Logic of Late Capitalism (Durham, NC:

Duke University Press, 1991), 50-54. Jameson usefully expands his understanding of the need for cognitive mapping in our current moment in "Cognitive Mapping" in Marxism and the

Interpretation of Culture, edited by Cary Nelson and Lawrence Grossberg (Urbana and Chicago: University of Illinois Press, 1988), 347-360.

6. In referring to the network as rhizomatic, I'm summoning the image explored in the opening pages of Gilles Deleuze and Félix Guattari's A Thousand Plateaus (Minneapolis: University of Minnesota Press, 1987), 3-25. This image has proved to be one of the more general strategies for cognitive mapping in this historical moment - used also, for example, by Michael Hardt and Antonio Negri in their books Empire (Cambridge, MA: Harvard University Press, 2001) and Multitude (New York, NY: Penguin Press, 2004).

7. For more on the physical structures of the internet, see Kris Paulsen, "Introduction (Part I) By Land, By Sea, By Air: The Physical Structures of Networked Art," Media-N 10, no. 3 (Fall 2010) or, for the mass-market version, Andrew Blum, Tubes (New York: HarperCollins, 2012).

8. A significant part of my film and the evolution of the project that didn't find its way into this essay is the environmental impact of the virtual economy. In some ways, these may be the most substantial transformations of all, given that they transform (in increasingly catastrophic ways) the world we all occupy. They're also some of the most elusive - the astonishing energy consumption of a Google search, a Bitcoin transaction, or the server farms where all this data is stored and processed - another kind of invisibility that this film seeks to reveal.

9. “Amazon's Latest Experiment: Retraining Its Work Force," The New York Times, July 11, 2019. https://www.nytimes.com/2019/07/11/technology/amazon-workers-retrainingautomation.html.

\section{AUTHOR BIO}

Roger Beebe is a filmmaker whose work since 2006 consists primarily of multiple projector performances and essayistic videos that explore the world of found images and the "found" landscapes of late capitalism. He has screened his films around the globe at such unlikely venues as the CBS Jumbotron in Times Square and McMurdo Station in Antarctica, as well as more 
likely ones including Sundance and the Museum of Modern Art, with solo shows at Anthology Film Archives, The Laboratorio Arte Alameda in Mexico City, and Los Angeles Filmforum, among many other venues. Beebe is also a film programmer: he ran Flicker, a festival of smallgauge film in Chapel Hill, NC, from 1997-2000 and was the founder and Artistic Director of FLEX, the Florida Experimental Film Festival from 2004-2014. He is currently a Professor in the Department of Art at The Ohio State University. 